\title{
Protected Cultivation of Horticultural Crops Worldwide
}

\author{
Sylvan H. Wittwer' and Nicolas Castilla ${ }^{2}$
}

$\mathrm{P}$ rotected cultivation, which enables some control of wind velocity, moisture, temperature, mineral nutrients, light intensity, and atmospheric composition, has contributed and will continue to contribute much to a better understanding of growth factor requirements and inputs for improving crop productivity in open fields. Protected cultivation is a unique and specialized form of agriculture. Devices or technologies for protection (windbreaks, irrigation, soil mulches) or structures (greenhouses, tunnels, rowcovers) may be used with or without heat. The intent is to grow crops where otherwise they could not survive by modifying the natural environment to prolong the harvest period, often with earlier maturity, to increase yields, improve quality, enhance the stability of production, and make commodities available when there is no outdoor production. The primary emphasis is on producing high-value horticultural crops (vegetables, fruit, flowers, woody ornamental, and bedding plants).

Production areas, structures, and crops have been expanding rapidly during the past century (see Sidebar). From the beginning, agricultural production has been primarily outdoors. It is a major industry that is primarily climate- and weather-dependent. In fact, the most determinate factor in horticultural crop production is the climate.

${ }^{i}$ Professor Emeritus, Department of Horticulture, Michigan State University, East Lansing, MI 48824-1325.

'Head, Dept. of Horticulture, Agricultural Research and Development Center, P. O. Box 2027, 18080, Granada, Spain. Other sources of information for the tables: Castilla (1992), El-Aidy (1992), Garnaud (1994), Germing (1985), Nishi (1986), Olympios (1991), Schales (1990), Tognoni (1991), Wittwer (1993), Wittwer and Robb (1964), Wittwer and Honma, (1979). We are grateful to the following for providing the data on protected cultivation in the various countries: L. Reguieg (Algeria); J.C. Zambo and J.C. Favaro (Argentina); F. Benoit and M. Sirjacobs (Belgium); Y. Solakov (Bulgaria); A. Aljaro (Chile); A.F. Abou-Hadid (Egypt); Lea Kurki (Finland); J.C. Garnaud and P. Printz (France); C. von Zabeltiz (Germany); C. Olympios (Greece); C. van Winden, M.v.d. Linden, and Ad. N. M. de Koning (Holland); K. Gerundas (Hungary); A. Braverman and A.H. Halevy (Israel); R. D'Amore (Italy); A. Ahdel-Nour (Jordan); H. Reyes (Mexico); R. Choukr-Allah (Morocco); P. Sivek (Poland); A. Monteiro (Portugal); E.J. Johansson and Asger Klougart (Scandinavia and Denmark); J.I. Montero (Spain); A. Mougou (Tunisia); K. Abak (Turkey); G.L. Bondarenko, (Ukrainia); J.T. Ashdown (United Kingdom); W.H. Carlson, Carl Hoefor, J.Kelly, W.J. Lamont, Jr., H. Grey, and O.S. Wells (United States). 
The magnitude of the impact of climate and weather agriculture productivity and quality of the product even now is appreciated only by farmers and a small segment of the scientific community, namely horticulturists, and hardly at all by the general population.

For example, the perceptive document Agriculture: Toward the Year 2001 (FAO, 1979) makes no mention of climate. Farmers appreciate and fear the impacts of weather. Climate remains the primary factor as to where food and fiber are produced and which crops are grown (Dalrymple, 1973).

Among the greatest constraints in horticultural crop production are a lack of sunlight, temperatures that are either too hot or too cold, moisture deficiencies or excesses, weed growth, deficiencies in soil nutrients, excessive wind velocity, and atmospheric carbon dioxide. Most of these are climatic factors or directly related to them. Many of these constraints have been alleviated or lessened by protected cultivation or controlled environments.

The lack of water is the single most important environmental impediment to plant growth and global food production. Water is our most precious and most wasted resource. The greatest crop losses in the United States from 1930-78 were caused by drought. Losses from drought were almost equal to all other climate-induced losses, including excess water, floods, cold, hail, and wind (Boyer, 1982).

By far, the most intensive and ancient means of protected cultivation of crops is irrigation. Windbreaks, the magnitude of which is not known, provide a second means. By irrigation, crop production has been extended to deserts and semi-arid lands that otherwise would be nonproductive. Many of the hazards of drought have been overcome.

The recent rate of increase of irrigated land has been precipitous. From 1950 to the early 1980s, the crop area irrigated in the world increased from 94 to 250 million ha (Postel, 1989). This increase accounted for $40 \%$ to $50 \%$ of the increase in agricultural output. While the expansion of irrigation in the late 1980s and early 1990s has slowed dramatically in the United States and elsewhere, some nations, such as China, anticipate further expansion. Today, $17 \%$ of the world's cropland that is irrigated produces a third of the agricultural output. Four countries-China, India, the United States, and Pakistan-contain half the world's irrigated land. More than two-thirds of all the food in China is produced on land that is irrigated, and more than half of the land in India, Indonesia, and Japan is irrigated. Irrigation technologies for China date back more than 2200 years to the construction of the $\mathrm{Du}$ Jiang Weir in what is now Sichuan Province.
World-wide agriculture claims two-thirds of all the fresh water removed from rivers, lakes, streams, and aquifers (Postel, 1993). Further expansion of irrigation is now limited by short water supplies in much of the United States, Russia, China, India, Pakistan, Spain, Italy, Mexico, Chile, and Australia and almost all Mediterranean, Arabian Gulf, and African countries. The high agricultural use of water is increasingly under challenge, from the standpoint of rising food costs and other competitive options such as recreation, municipalities, industry, energy generators, and the current low efficiency (35\% to $40 \%$ ) for agricultural use. Coupled with irrigation of high-value crops has been the rise in the use of the highly efficient drip or trickle systems, which, at the global level, now comprise between 1.5 and 2.0 million ha. Drip irrigation systems are frequently an important component of other structures designed for protected cultivation of horticultural crops.

Controlled-environment agriculture or protected cultivation has now extended far beyond the realms of crop irrigation and water management. The focus of this paper is mostly on structures and technologies, other than irrigation, that have emerged largely during the past century.

\section{Types of plant protection}

All plant species have an optimal range for each environmental factor. Installing a screen or shelter alters the energy and other exchanges between the whole plant (or apart of it) and the environment. The position of the screen or shelter, relative to the plant, determines the kind of protection. In mulches, the screen is located below the above-ground parts of the plant, over the soil. Greenhouses, tunnels, and direct covers are other types of protection, where the screen is placed over the plants as a cover. Windbreaks are placed laterally to the crop (CPA, 1992).

Windbreaks. Windbreaks are used for mechanical protection, particularly for vine crops, as protection against the whipping of the wind, which reduces evapotranspiration. Windbreaks enhance early maturity, improve growth, increase production, and result in a better-quality product. The action of wind on crops is direct and indirect. It induces morphological and anatomical changes, similar to those produced by drought; reduces photosynthetic activity, and increases evapotranspiration (FAO, 1986). On bare soils, wind erosion can be very destructive, especially in arid regions and deserts. The main advantage of windbreaks is to reduce crop damage either from breaking and drying, particularly of the stems and leaves of vine crops, or blowing particles that affect the

\section{The lack of
water is the single most im- portant environ- mental impedi- ment to plant growth and global food production.}




\section{Historical Perspective of Protected Cultivation}

Attempts to adapt crop production to the environment with protective devices or practices dates back to ancient times. Structures for crop protection began in the early part of the Roman Empire to accommodate the Emperor Tiberius Caesar (14-37 AD). They consisted of movable beds of cucumbers, and perhaps other crops, placed outside on favorable days and inside during inclement weather. Transparent slatelike plates or sheets of mica or alabaster were used as covers. Such cultural methods ceased with the decline of the Roman Empire (Dalrymple, 1973).

It was not until the late 15 th to 18 th centuries that the precursors of greenhouses appeared, primarily in England, Holland, France, Japan, and China. They were crude square or rectangular wooden or bamboo frames or structures covered with panes of glass, oiled paper, or glass bells to cover hotbeds. A wide variety of out-of-season vegetables and small fruit were grown. During the late 1600 s to 1700 s, stoves and heating flues began to be used with the first glass greenhouses. They had glass on one side only in the form of a sloping roof. Later in the 18th century, glass was used for the front and on both ends of lean-to houses (Dalrymple, 1973). The two-sided greenhouse emerged in the 1800s. Leading in those early developments were England, Holland, France, and the Scandinavian countries. Forcing crops became especially popular in England during the late 1700 s to 1800 s. Produce was no longer confined just to the wealthy. By the middle of the 1800s, greenhousegrown grapes, melons, peaches, and strawberries appeared on English markets,and then tomatoes from the 1870 s to 1880 s. By the end of the 19th century, commercial greenhouse crop production was wellestablished.

The development of forcing frames and greenhouses soon spread from Europe to America and elsewhere. In China, Japan, and Korea, near the major cities, glass greenhouses were built low, with glass only on the roof and southern wall, The northern and side walls were constructed of either concrete or adobe embanked with bales of rice straw for insulation, These houses were devoted to producing cucumbers, tomatoes, eggplant, and beans. Many were not heated, but were covered with straw mats at night (Romanowski, 1981).

In the United States, several kinds of structures were built between 1700 and 1800 with varying degrees of protection

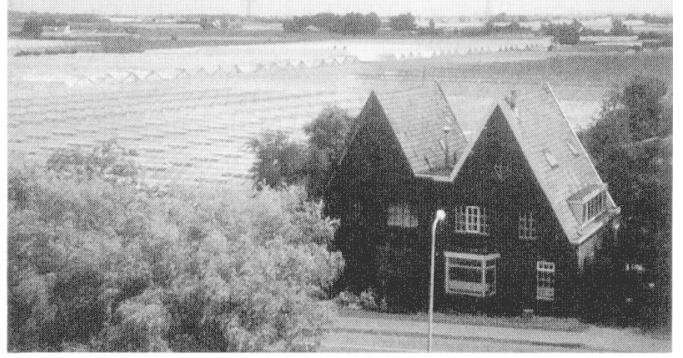

Fig. 1. Thousands of small glass greenhouses were devoted to table grape production in Belgium during the 1950s and 1960s.

tories in New York and Washington. Waltham, Mass., near Boston, with its research station, was a focal point for forcing vegetables, first in hotbeds and then greenhouses. Lettuce and radishes were the first crops to appear in the 1860s, followed by cucumbers and then tomatoes. Growth in the Boston area was followed by expansion around Grand Rapids, Mich., and later near Cleveland and Toledo, Ohio, By the turn of the century, there were an estimated 1000 greenhouses in the United States devoted primarily to forcing winter vegetables, with an annual retail value of about $\$ 4.5 \mathrm{mil}-$ lion. By 1929, there was 550 ha of veg- Fig.2. Forcing rhubarb in mid-winter in Michigan and etables raised under glass in the United elsewhere was a common practice during the middle States in 20 th century. Two-year-old roots were harSlates, valued at the farm level at about $\$ 10$ vested in the fall and held in darkness in special million. Almost double that area was de- heated houses to stimulate growth. voted to flowers and ornamentals. For vegetables, tomatoes represented $43 \%$ of the

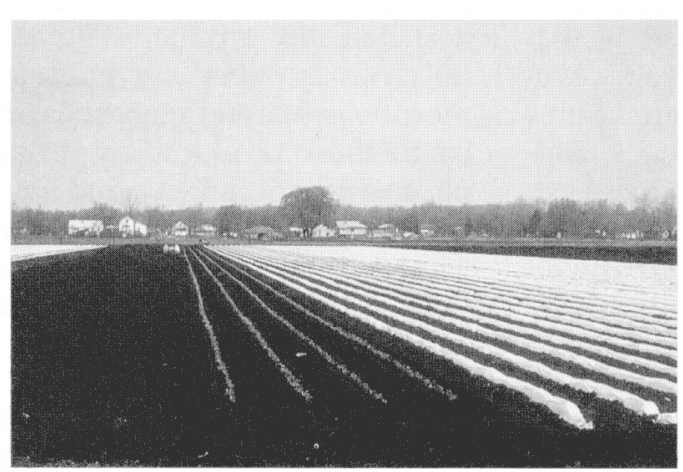

Thousands of small units (Fig. 1) were devoted to table grape production in Belqium in the 1950s and the earlv1960s. Simultaneously, in Michigan, a \$2 million dollar industry emerged: foreing rhubarb (Fig. 2) in heated houses during winter and covering rows of early transplanted field celery with parchment paper (Fig. 3). Now, how-

Fig. 3. Rows of newly transplanted celery plants covered with tunnels or tubes of parchment paper for protection against spring frosts, wind, snow, and rain in Michigan. 


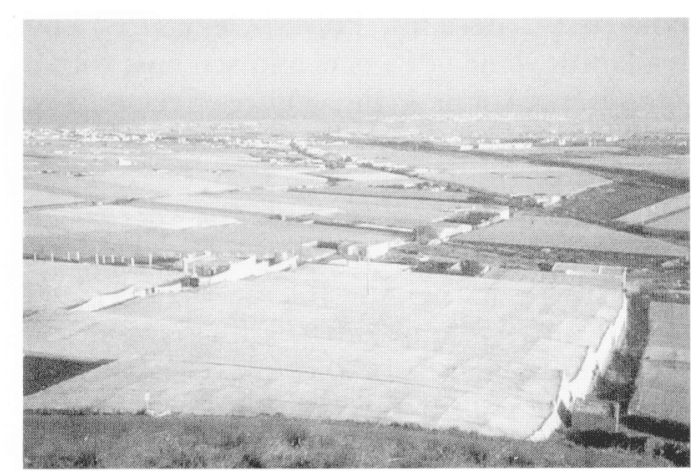

Fig. 4. Entire valleys are covered with plastic greenhouses west of Almeria, Spain.

ever, these two types of vegetable forcing or protected cultivation are almost nonexistent.

In the United States, dramatic changes have occurred since the 1960s in crops grown in greenhouses. Hydroponic culture, especially for tomatoes, became an attractive and expensive venture. Such units became widely distributed across the nation (Jensen and Collins, 1985). As late as the 1960s and early 1970s, there was more than 400 ha devoted to vegetable production (primarily tomato, cucumber, and lettuce). That hectarage has now diminished to less than 100 ha. Of total greenhouse production, scarcely more than $5 \%$ is vegetables, the balance being flowers, potted plants, ornamental, and bedding plants.

By 1980, there were an estimated 150,000 ha of greenhouses (glass, fiberglass, plastic) globally for high-value food crops (Wittwer, 1981). Annual gross productivity ranged from $\$ 20$ to $\$ 40$ billion. In addition, about 50,000 ha was devoted to

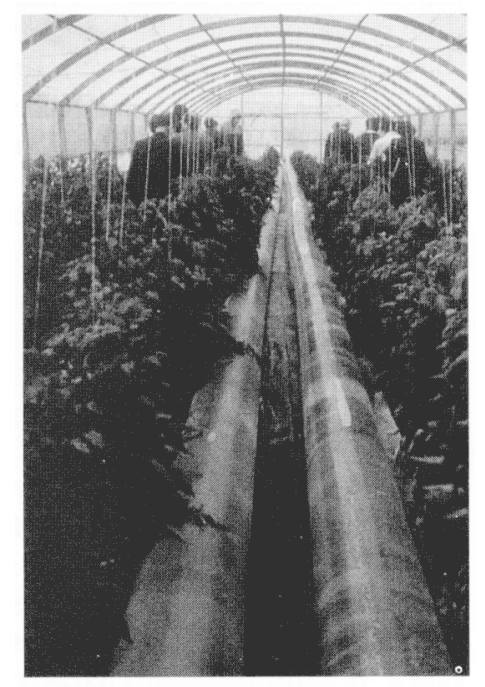

Fig. 5. Double protection for melons-minitunnels inside a plastic greenhouse in Almeria, Spain. the production of flowers, ornamental, and bedding plants.

Meanwhile, other areas, particularly in Asian and Mediterranean countries, witnessed a phenomenal increase in greenhouse culture of high-value vegetable crops, originating with the use of plastic for nonheated greenhouse construction beginning in the 1950s. This is reflected in current data, which show that the production of vegetables in Europe has been shifting south to the Mediterranean area, where they are grown in plastic tunnels and greenhouses (Figs. 4 and 5). Meanwhile, there has been a shift in northern European glass greenhouses to added-value crops of ornamental, flowers, and potted plants. The expansion in plasticulture in the Medi-

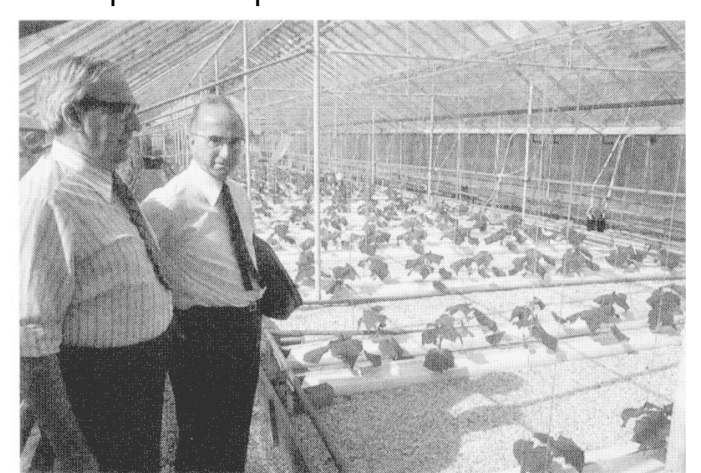

Fig. 6. A.J. Cooper (left) and G. W. Winsor (right), originators of the nutrient-film technique of the Glasshouse Crops Research Institute in Little Hampton, U.K.

terranean is still gaining momentum, again with a gradual transition from the production of food crops to flowers, potted and bedding plants, and ornamental. Nowhere were these expansions and transitions greater than in China and the Mediterranean countries, with Spain and Italy as leaders. They were accompanied by a likewise remarkable increase in drip irrigation, originating in Israel during the 1960 s and traveling to the United States in 1970, when there was a worldwide hectarage of about 2000. By 1974, this had grown to 65,000 ha, with about 200,000 in 1978 and 500,000 hectares by 1980 (Wittwer, 1981).

Concurrently with all these developments of plastic greenhouses and expansion of areas covered and protected by windbreaks and with drip irrigation has been an ever-expanding use of plastic row tunnels, covers, and plastic soil mulches, with an enormous increase in China (Wittwer et al., 1987), where currently an area of more than 2.8 million ha of crops is covered with plastic soil mulch. Meanwhile, a remarkable set of automated plant-growing technologies, including the nutrient-film technique developed at the Glasshouse Crops Research Institute in Littlehampton, U.K. (Fig. 6), was followed by the construction of the first phytotrons and plant growth chambers. Finally, free air $\mathrm{CO}_{2}$ field experiments are in progress for evaluating the impact of rising levels of atmospheric $\mathrm{CQ}$ for the enhancement of plant growth, initially observed over a century ago for crops grown in some of the first glass greenhouses constructed in western Europe (Wittwer, 1986).

In the Westlands and elsewhere in Holland today, where much of the exploratory work on protected cultivation had its origin more than 2 centuries ago, there is more than 10,000 ha covered by glass greenhouses, with the area increasing each year, devoted to the year-round production of high-quality vegetables (tomato, pepper, eggplant, cucumber, lettuce), cut flowers (rose, chrysanthemum, carnation, tulip, lily), and potted plants (ficus, dracaena, kalanchoe, begonia, azalea). Carbon dioxide enrichment, along with other high-technology inputs (differences in day and night temperature), artificial substrates (media), bottom heat, and precise control of the growth inputs of water, temperature, and nutrients to maximize use of sunlight, is used throughout the entire year. The atmospheric level of $\mathrm{CO}_{2}$ is maintained at 750 1000 ppm even during summer. During summer, natural gas is burned just for $\mathrm{CQ}$ The heat produced is stored in water tanks to elevate night temperatures. The benefits of $\mathrm{CO}_{2}$ enrichment result in higher yields, earlier harvests, and improved quality for all crops. Research is now focused on storing the heat released from the combustion of natural gas to achieve high daytime levels of atmospheric $\mathrm{CO}_{2}$ in the greenhouse environment and computer tracking of needed inputs (Nederhoff, 1994). A counterpart is found in the latest technological inputs for bedding plant production in the United States (Erwin et al., 1993). 


\section{The most- efficient windbreaks must have an optimal permeability of $40 \%$ to $50 \%$.}

Fig. 7. Windbreaks made from dry cane (Arundo donax) are popular in the Mediterranean.

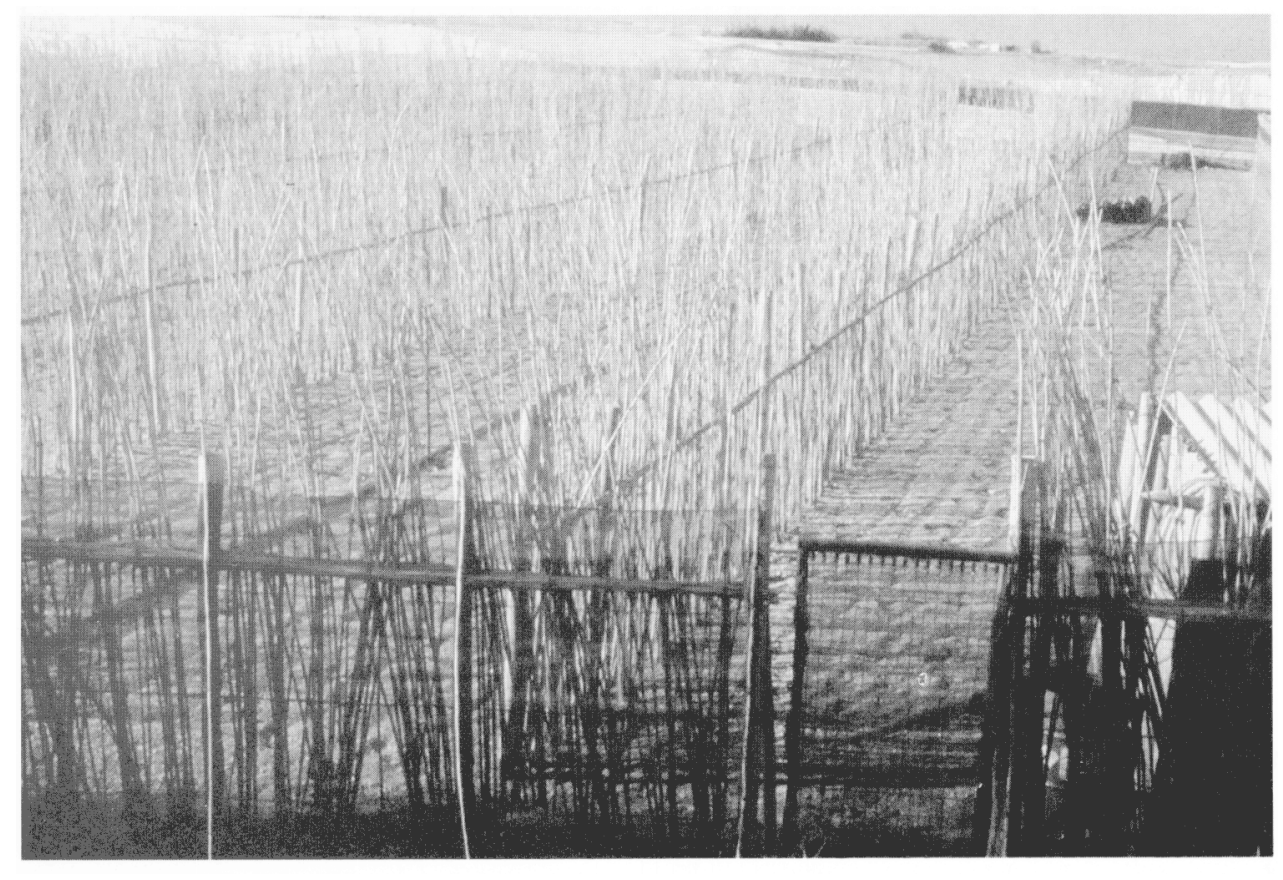

the past 2 decades. Polyethylene (PE) and polypropylene $(\mathrm{PP})$ nets and screens, with a preference for nets (Fig. 8), are effective. The structural framework for a windbreak may consist of wood, bamboo, iron, or concrete posts reinforced with wire. The species selectedfor natural windbreaks is based on rate of growth in height, foliage density, and uniformity; adaptation to climatic and soil conditions; depth of rooting; resistance to wind; and continuous protection for all seasons.

Themost-efficientwindbreaksmusthave anoptimal permeability of $40 \%$ to $50 \%$. Dense windbreaks greatly reduce the wind directly behind, but generate eddies and strong turbulences in the nearby vicinity. The horizontal range of wind reduction by a windbreak, expressed in percentage, is proportional to its height,andis practically independent ofwind speed. The optimum distance between windbreaks of the permeable type is 15 and 25 times the height (FAO, 1986). Rectangular networks, found extensively in northern China, account for variations in wind direction and usually give the best wind protection. Aside from mechanical plant protection, the main effects ofwindbreaks on yields result from an increase in the air temperature duringthedayandimprovedmoisture conditions. A combinationof natural and artificial windbreaks may be advised (CPA, 1992).

Soil mulches. Soil mulches of straw or crop or plant residues, including other living crops, sand, gravel, and rocks, are used on a widevarietyof crops, including strawberries, tomatoes, peppers, asparagus, melons, $\mathrm{cu}^{-}$ cumbers, squash, banana, and sweetpotato. Mulching is the application of a soil cover that is a barrier to the transfer of heat or vapor. Mulches reduce the energy used in evaporation of water from the soil surface and competition fromweedgrowth. They effectively block the transport of vapor out of the soil, altering net radiation at the soil surface (Rosenberg, 1974). Different kinds of mulches have been used from ancient times. In situ materials, such as weeds and otherresidual plant or crop materials, may be dried and spread as a layer over the soil. Straw mulches have been used worldwide. Living mulches of grass, although often referred to as such, are not real mulches, for they do not constitute a barrier to the transfer of heat or vapor,butimprovesoil characteristics and fertility and alter the microclimate. Water consumption may be increased.

Manufactured or processed 
mulching materials include paper of various textures and colors, aluminum foil, graded gravel, sand, and many kinds of plastic films. Small stones constitute a natural mulch in gravel-type soil when they rise to the surface from tillage. Gravel of volcanic origin also has been used for mulching. It is often more effective than natural organic mulches in that water is stored in its internal pores. Such gravel is used for mulching in the Canary Islands and in north-central China. Sand is used in the Mediterranean as a mulch (Castilla et al., 1986; Castilla and Fereres, 1990a). This allows use of low-quality irrigation waters.

Mulching crops during the past 3 decades has been prompted by the use of plastics (Wittwer, 1993). Low-density PE film is used universally. The use of linear low-density PE has allowed a decrease in thickness because it has greater mechanical resistance. A recent review (Lament, 1993 ) emphasizes that the advantages of plastic mulches are increased earlier and higher-quality yields, better weed control and insect management, and increased efficiency of the use of irrigation water and fertilizer. There is reduced surface evaporation, fertilzer leaching, and soil compaction. Disadvantages of plastic mulching are the necessity of removal, disposal after use, and the high initial cost.

Black, transparent, and white colors prevail in commercial mulching, but co-extruded white and black PE film is increasingly being used in developed countries. Transparent film acts in a similar manner to a greenhouse. The condensate on the underside of the film is opaque to long-wave infrared radiation and thus limits heat loss. Soil temperatures during the day, compared to bare soil, are higher under transparent and black films and slightly lower under the white (Lament, 1993). The crop canopy, however (shading of the film), can alter these patterns. Reflection into the plant Canopy of incoming solar radiation with white or co-extruded white-on-black and silver mulches at high latitudes increases available radiation for greenhouse crops. During cold seasons, transparent film is preferred to black, if weeds can be controlled efficiently in nontropical climates. When weeds are the prevailing problem, black-onwhite should be used rather than black. Colored PE mulches reflect different radiation patterns of red and far-red light into a crop canopy. These consequent effects on photosynthetic efficiency and plant morphogenesis may increase yields (Decoteau, 1989).
Recent developments include mulches that selectively absorb photosynthetically active radiation (PAR) and transmit solar infrared radiation, thus combining the herbicide effect of black film with the thermal effect of transparent film (CPA, 1992 ). However, the herbicide effectiveness may not be total. A PE film impregnated with herbicide has been developed in Japan. Mulches with aluminum or silver surface colors repel some aphids and reduce the incidence of aphid-borne viruses (Lament et al., 1990). Yellow plastic film is useful in reducing whitefly populations (Bemisia tabaci) in young tomato plants. The flies are attracted by the yellow color of the heated plastic as it is exposed to the sun, when the plants are small and the crop canopy does not shade it (Geisenberg and Stewart, 1986).

Soil solar disinfection or polarization, using transparent plastic mulch in high solar radiation areas (Katan, 1980), has developed in certain latitudinal regions of California, Israel, Australia, and Spain. The soil temperature increase has been effective in reducing the incidence of Fusarium, Verticilium, and Sclerotinia and significantly limiting the presence of some weeds. Several weeks near the summer solstice are necessary for proper polarization. Deep thermal conduction of heat into the soil is improved if the soil profile is properly moistened. Solarization, combined with soil fumigation at low levels of fumigant, has proved effective for controlling soil-borne diseases and is environmentally friendly (Melero et al., 1989).

Photodegradable and biodegradable films are available commercially, but they have not been adopted widely because of their variable rates of degradation.

Plant covers. The most visible compo-

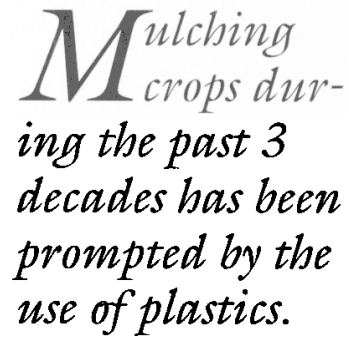

Fig. 8. Plastic nets are replacing the conventional dry cane windbreaks of the Mediterranean.

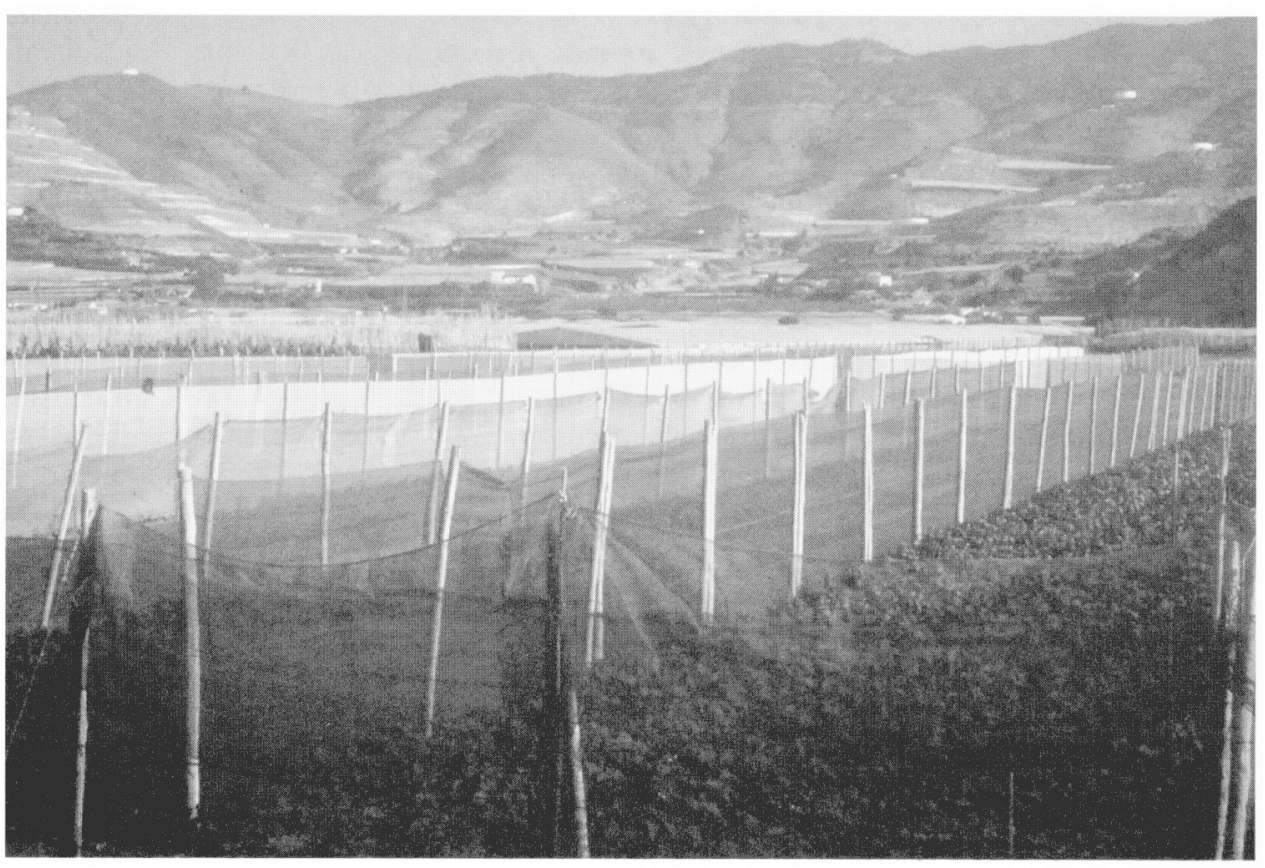




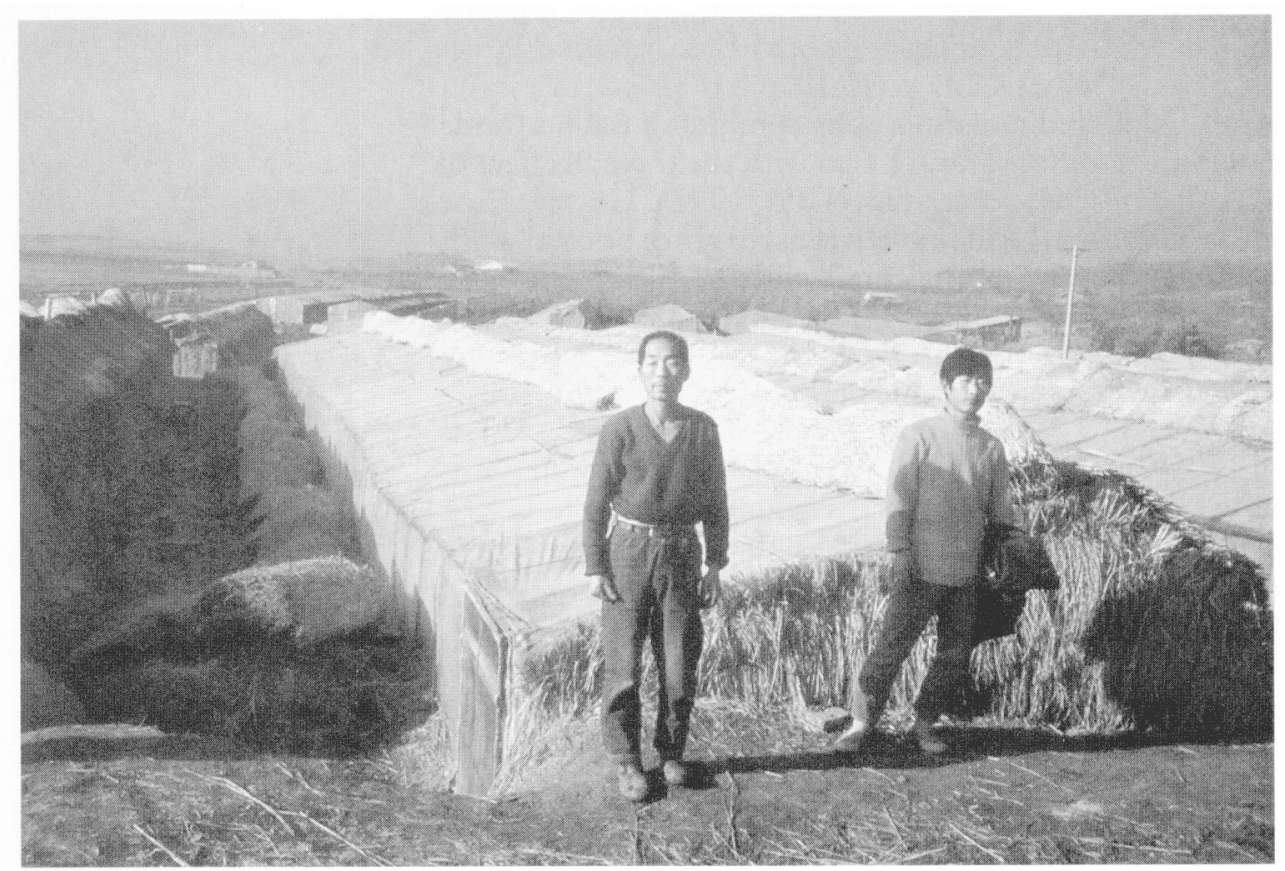

Perforated PE is preferred along with occasional use of ethylene-vinylacetate (EVA) film. The perforation number $(1 \mathrm{~cm}$ in diameter) lies between 500 and 800 per square meter consisting of $4 \%$ to $6.4 \%$ of "cover area (CPA, 1992). PE film with small fissures and plastic nets are used occasionally. Nonwovenmaterials are normally made of PP or polyester (PET).

Low tunnels. Low tunnels are small structures that provide temporary crop protection. They arealsoknown as rowcovers. Their height is generally $1 \mathrm{~m}$ or less, with noaislesforwalking.Cultural practices must be performed from the outside. Their use enhances early and total yields and they offer protectionagainstunfavorableclimatic variables (CPA, 1992 ). Thermal films of infrared PE, EVA, copoly-

Fig. 9. A combination of high and low technology may be seen in plastic greenhouses in Korea.

\section{Tovers that transmit}

sunlight are essential for growing plants. nents in protected cultivation are light-transmitting covers that protect plants from the environmental hazards of adverse temperatures, wind, hail, rain, and sun. Covers that transmit sunlight are essential for growing plants. It is not economically feasible to grow plants with artificial lights, except under special circumstances or for experimental purposes. Artificial lighting, however, may be used as a supplement to sunlight and to extend the photoperiod. A cover over and around plants affects the enclosed microclimate as it alters the light and temperature, wind speed, air and soil humidity, and the atmospheric composition. The different types of protection involving placing a screen over the plants include direct covers, tunnels, and greenhouses.

Direct covers. Also known as floating mulches, direct covers consist of a screen of perforated plastic or nonwoven film (CPA, 1992 ), and offer simple, cheap, and effective semi-protection. Plants and soil are directly covered and there is no framework. Plants under direct covers benefit from the greenhouse effect of higher daytime temperatures and a windbreak effect of reducing evapotranspiration. The cover protects plants and soil from high-intensity rainfall and hail (Benoit andCaustermans,1985;Wellsand Loy, 1985 ). Theprotectionperiodwithdirect covers can be during a small 'part of or the entire growing cycle. Direct covers. also provide protection againstinsectsandbirdsand are environmentally friendly. They reduce the need for pesticide sprays and also reduce the incidence of insect-borne viruses. Plant uniformity is improved, fruit quality enhanced, the harvest season extended, and total yields increased (CPA, 1992). mer, polyvinylchloride (PVC), and conventional PE are being used worldwide (CPA, 1992).

High tunnels. Also known as walk-in tunnels, high tunnels are protective structures tall enough that the crop can be manipulated from within. Moderately tall crops can be cultivated in high tunnels, although planting near sidewalks is limited. Statistics for high tunnels are often included in the samecategoryaslow-costplasticgreenhouses, because the cladding or covers are similar. Claddingmaterialsarepracticallythe same as those used in low tunnels.

Greenhouses. Greenhouses differ from other protection structures in that they are sufficiently high and large to permit a person toconvenientlystanduprightandworkwithin (Nelson, 1985). Although there were many early attempts, greenhouses did not appear untilglasswasavailableforcladding. This was followed by the introduction of plastic films, which resulted in a worldwide greenhouse industry. Greenhouses protect crops against cold, rain, hail, and wind and provide plants with improved environments over those grown in open fields. (CPA, 1992). Furthermore, in greenhouses, crops can be produced out-of-seasonyear-roundandtheir yields and quality are higher than those grown in open fields. Greenhouses also have allowed the introduction of crops normally foreign in that region (Germing, 1985 ).

There are two basic types of greenhouses. One type seeks maximum climatic control in an environment that optimizes productivity. The other type provides minimal climatic control, enabling the plants to survive and produce an economical yield (Enoch, 1986). These two types are characterized by the 
contrasts in the northern and southern European greenhouse industries (Castilla, 1994; Castilla and Fereres, 1990 b). In the north, optimal conditions for year-round production are provided in the glass greenhouses of Holland, the United Kingdom, and Scandinavia. In the Mediterranean region, the unheated plastic houses adapt the plant to suboptimal conditions (Castilla et al., 1992; Tognoni and Serra, 1989). The technologies for environmental control in the greenhouses of northern Europe, the United States, Japan, and elsewhere have been characterized by many new developments during the past 3 decades. The variables of light, temperature, air and soil humidity, and $\mathrm{CO}_{2}$ content of the atmosphere are computer-programmed $24 \mathrm{~h}$ a day to achieve maximum crop yields, all as a part of dynamic climate control systems (Nederhoff, 1994; Seginer, 1993). Further refinements in adjusting the greenhouse climate to optimal crop productivity and resource inputs can be expected. Choice of a greenhouse type depends on the cultivated crop, its location, and financial resources. There is a strong relationship between local conditions, greenhouse design, cladding materials, and insulation needs (Germing, 1985 ). The original greenhouse function has been changed for some climatic zones from a greenhouse effect to either that of an umbrella or oasis effect. The umbrella effect is found in the rain shelter used in humid tropical and subtropical climate areas. The roof is covered with film but the sides are left open (Garnaud, 1987). The oasis effect is found in greenhouses in arid tropical or subtropical regions. Light intensity and evapotranspiration are reduced and minimum temperature is increased (Nissen et al., 1990).

The structure of a greenhouse depends on the climate and the cladding used. There are various roof, space, and height geometries with single-span materials such as wood and bamboo, which are used frequently in low-cost structures, particularly in China and in semitropical and tropical areas. Claddingmaterials were limited to glass until the middle of the 20th century. Beginning in the 1950s, plastic films, because of their low cost, light weight, and adaptability to different frame designs, generated a great increase in structures, especially in the semi-tropics and in more benign climates than those of northern Europe (Nelson, 1985).

Conventional and modified (infrared, UVlong-life anticondensate PE) films, together with PVC, prevail worldwide. New co-ex- truded films combine in one film the advantages of different layers of materials. Rigidly structuredplasticcoveringsinsingle or double layers have had limited acceptance. They are costly, but offer interesting possibilities. Fiberglass-reinforced polyester (FRP), polymethylmethacrylate (PMMA), polycarbonate (PC), and PVC are the usual materials in rigid plastic panels. The diversity of greenhouse coverings has been reviewed recently (Giacomelli and Roberts, 1993). All coverings can perform well, depending on the desired use and location. Single plastic film prevails in warm climates; inflated double plasticfilmorrigid single plastic panels would be adequate for cool areas. For cold areas, glass or twin-wall rigid plastic panels would be best (Germing, 1985 ). A combination of high and low technology may be seen in Korea (Fig. 9). Plastic covers for greenhouses in northern Europe are not acceptable because of low light transmission compared to glass. Selection should also take into account crop requirements, cost, and how to achieve the highest financial returns (Castilla, 1994). Covering greenhouses with nets is common in tropical areas or during hot weather in temperate zones. The nets reduce pest damage and the extremes of temperature and air humidity.Theyalsoprovide a windbreak and reduce the damage from heavy rain and hail (Castilla, 1994).

\section{Objectives and advantages}

The overall objective of protected cultivation is to modify the natural environment by practices or structures to achieve optimal productivity of crops by enhancing yields,

\section{The operall lobjective of protected culti- vation is to modify the natural en- vironment by practices or structures...}

Fig. 10. Plastic mulching of sweetpotato in Nigeria.

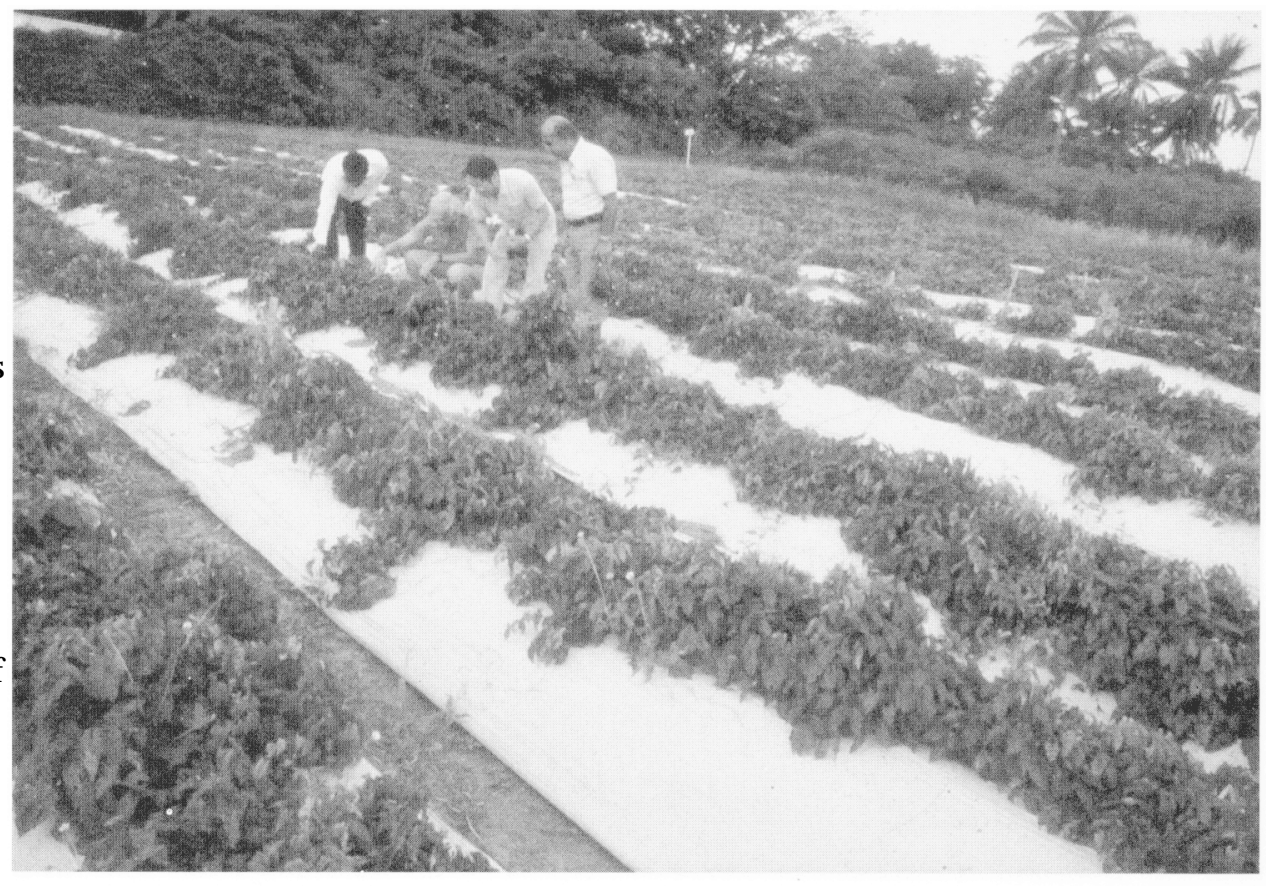




\section{Windbreaks ally important for all vine crops...}

Fig.11. Living windbreaks for protecting watermelons in China. imprving quality, extending the effective harvest period, and expanding production areas. There are also specific objectives and advantages in selected geographical areas for limiting rainfall and hail damage and reducinghighsun radiation by shading. The overall intent is the most effective use of land, water, energy, mineral nutrients, and space, and the climatic resources of sunlight, temperature, relative humidity and atmospheric $\mathrm{CO}_{2}$.

Protecting crops from drought. Watermanagementthroughirrigationanddrainage systems is nearly global in practice and impact. Water shortages for high-value horticultural crops prevail in some areas in almost all countries and during part of the growing season in others. Irrigation may supplement the natural precipitation in the eastern and Midwestern United States and in many parts of Europe or provide the entire water requirement in the southwestern United States and Egypt.

Reducing water requirements. Plastic soil mulches, organic residue mulches, rock, gravel, and sand mulches are used extensively in areas with limited soil moisture to reduce evaporative water losses from soil surfaces and competitive weed growth. Rock and sand mulches have been used for centuries in the semi-arid lands of northwestern China. Plastic mulches are being used in such diverse areas as Nigeria to control weeds and improve yields of sweetpotatoes and cassava (Fig. 10) to European Mediterranean countries to reduce water requirements.

Protecting crops in open fields from frost and freezing. Crops have been protected in restricted areas through use of overhead sprinkle irrigation for strawberries and vegetables (tomatoes, peppers, melons) and forseveralflower and ornamental crops.Wind machines, solid set heating systems, and smudge pots have also been used for limited protection of fruit orchards in the United States and elsewhere.Plantandrowcoversinvolvingsoil, parchmentpaper, glass, and plastics (floating and rigid), have been, and are still, used for frost-susceptible crops, involving continuous low tunnels over the crop row. Specific examples are strawberries, melons, cucumbers, tomatoes, peppers, and celery.

Reducing wind damage. Windbreaks are especially important for all vine cropsmelons,cucumbers,squash-andhelpfulwith all high-value horticultural crops. Windbreaks, either from living crops (Fig. 11) or structures, are used widely in the Mediterranean countries, almost all of China, Japan, and Korea, and in many parts of the United States and Canada.

Lessening the impact of hot arid lands. Cooling is achieved by evaporation andforcedair circulation within greenhouses. It has been found especially important in the southwestern United States, Mexico (Fig. 12), Arabian Gulf, and Mediterranean countriesthat produce small fruit, vegetables, and flowers. Cooling also substantially reduces the requirement for flesh water.

Reducing damage from insects, diseases, nematodes, weeds, birds, and other predators. Within the environment of a greenhouse, fumigation of the soil and atmosphere is feasible. Soils may also be removed and replaced. Artificial root-growing media (bag culture, rock wool, nutrient film technique, or other forms of hydroponics) have replaced soil culture in many growing areas, including Holland, the United Kingdom, the United States. and most of Scandinavia, especially Denmark. Thus, many soilborne diseases and pests have been controlled or eliminated. Plastic nets over fields of strawberries and other high-value crops, often under plastic covers and grown with soil mulches, coupled with drip irrigation, are used in Israel (Fig. 13) and the Mediterranean countries of southern Europe and northern Mica. Soil solar disinfection (polarization)usingplasticmulch is an effective and environmentally friendly technique, used widely in high light intensity.

Extending production areas and growing seasons. Production has been extended by usingglassandplastic structures, with or without heating (greenhouses, lowtunnels, and high tunnels), and soil mulches throughout Europe, theMediterranean,NorthAmerica, 
China, Korea, Japan, and many countries in the southern hemisphere,specificallywatermelons in northern Chinese provinces, tomatoes and cucumbers in Alaska, and the local availability of tomatoes, peppers, cucumbers, and many flower and ornamental crops in all northern European countries.

Increasing crop yields, im-

proving quality, and conserving resources. Protected cultivation, in its various forms, efficiently uses the natural resources of land, water, sunlight, energy, and atmospheric $\mathrm{CO}_{2}$. Simultaneously, yields maybe increased several-fold over thoseinopen-fieldagriculture. Furthermore, production per unit of landareaisstillincreasing.Twentyone years ago (1974), yields of tomatoes grown in the glass greenhouse of the Westlands of Holland was $15 \mathrm{~kg} \cdot \mathrm{m}^{-2}, 10$ years ago it was $40-45$ $\mathrm{kg} \cdot \mathrm{m}^{-2}$, today it is more than $60 \mathrm{~kg} \cdot \mathrm{m}^{-2}$, with a projected potential increase to $100 \mathrm{~kg} \cdot \mathrm{m}^{-2}$. Indeterminate crops (tomatoes, cucumbers, peppers) in greenhouses or high tunnels may be grown for extended periods beyond that of open-field agriculture in all temperate zones, or several crops maybe grown during the same year. Improved quality is a result of vine-ripe harvests, and improved appearance is a result of protection against wind, rain, hail, and damage from insects, birds, and other predators.

Controlling day and nigbt temperatures and photoperiod to optimize product maturity, productivity, and quality. Elevated root temperatures are important in the production of greenhouse-grown tomatoes and cucumbers and are widely used in northern Europe, resulting in the placement of heating units in or near the rooting media. Adjusting day and night temperatures to control plant growth is revolutionizing production practices for many flower and vegetable crops (Erwin et al., 1989). The recent concept of DIF (the difference between day and night temperatures) is now being used by growers of many flower and ornamental plants and may be useful for tomatoes, beans, and melons to control plant growth, height, and productivity (Heins and Erwin, 1990). Such control is only possible with some degree of enclosure with protected cultivation.

Controlling atmospheric $\mathrm{CO}_{2}$ level. Greenhouses and tunnels (plastic or glass) provide unique structures for the $\mathrm{CO}_{2}$ enrichment of atmospheres for enhancing plant growth. The beneficial effects of elevated levels of atmospheric $\mathrm{CO}_{2}$ were observed more than 100 years ago in western Europe and in the United States. Commercial enrichment was first produced in the Westlands of Holland in the early 1950s (Wittwer, 1986). Widely used in commercial protection of winter and spring flower and vegetable crops and for bedding plants in the United States, its most extensive use is in Holland's 10,316 ha of glass greenhouses. Enrichment to 750$1000 \mathrm{ppm}$ is practiced widely to increase production and plant density.

Stabilizing the market for high-quality horticultural products. Protected cultivation circumvents many of the hazards of climate and weather and greatly increases dependability and chances for availability. The Dutch have achieved this for manyflower and vegetable commodities, not only for domestic use but for many foreign outlets. Gourmet melons and fruit are produced in Japan for elite local and foreign outlets. The Mediterranean area is now a dependable source of winter and early spring vegetables and is becoming such a source of flowers and ornamental for northern Europe. In China, where consumption is high, there is a continuous supply of watermelon from early spring to late fall, thanks to windbreaks and plastic mulches and covers. There is now a dependable source of high-quality bedding plants in the United States, beginning in early spring and continuing through mid-summer.

Finally,controlled-environment agriculture, in contrast to open fields, offers a continuing technological challenge to the innovative home gardener. Millions of amateur and some professional gardeners use miniature windbreaks, plant protectors, plastic mulches (floating and rigid), and tunnels. These are often coupled with drip irrigation
Fig. 12. Plastic greenhouses in desert areas give wind protection, reduce the requirement for fresh water, and provide evaporative cooling.

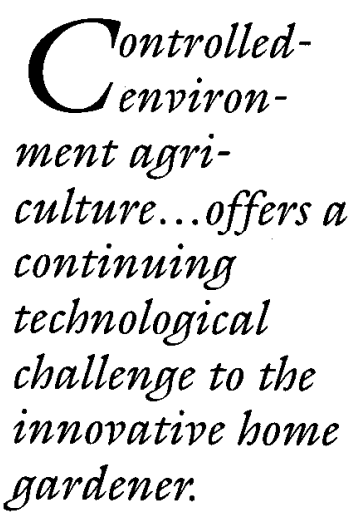

ment agri-

culture...offers a

continuing

technological

challenge to the

innovatipe bome

gardener. 


\section{The most extensive use of windbreaks, artificial and natural, is found in China, Russia, and Ukraine.}

systems,small greenhouses, and sometimes a degree of hydroponics to hasten maturity, increase yields, and extend the growing seasonsforhigh-quality home-grown fruit, flowers, and vegetables. This is especially typical ofgardens in Europe, Korea, China, and parts of the United States (Fig. 14).

\section{Present status and outlook- major areas of production}

Historically, using windbreaks predated by many centuries (Table 1 ) those of protective structures such as tunnels and greenhouses. There is no accurate estimate of areas involved, and no distinction is made between either the natural or artificial windbreaks or soil mulches. Other crops than those protected are found particularly in China, where grain crops, before harvest, are often used to shelteryoungwatermelonplants.Plasticwindbreaks are rapidly replacing wood or bamboo canes in the Mediterranean countries to shelter tender vegetable and flower crops and even entire ranges of plastic greenhouses or tunnels. The most extensive use of windbreaks,artificialandnatural,isfoundin China, Russia, and Ukraine. Windbreaks are similarly used for large volumes of high-value crops in all southern countries of Europe and northern countries. of Mica bordering the Mediterranean and Canary Islands. During the past 2 decades, a tremendous transition and expansion in the use ofplastic soil mulches has occurred, especially in some of the Mediterranean countries and in China, Japan, and Korea. The world's most extensive uses of plastic soil mulches (not listed in Table 2) are now in China for cotton, peanuts, rice seedbeds, and corn.
The generalized use ofphotodegradable mulch film is limited to the corn crop in France. Mulching is increasingly being combinedwithdrip irrigation. Clear or black films are preferred. Greenhouses, glass and plastic, and plastic tunnels high and low, constitute the structures most commonly associatedwith protected cultivation of crops. They are highly visible,haveadegree of permanence, and pose a continuing attraction and enchantment by the enclosed environments created, the crops grown, and the facilities for automated irrigation, nutrient feeding, and root media and plant support systems. Worldwide, there are two vast areas of greenhouses-one of glass in the Westlands of Holland near the village of Naaldwijk between Rotterdam and Den Hague, the other ofplastic along the seacoast valleys near Almeria, on the Mediterranean Sea in southern Spain (see Sidebar). Other prominent expanses of glass or plastic or both can be seen in China, Japan, Italy (Sicily), Greece (Crete), Essex County, Ontario, west of Cleveland, San Diego County, and the Isle of Guernsey, U.K. Table 2 summarizes the global distribution ofhorticuhural crops most commonly grown under protective structures. The principal greenhouse-grown vegetable crops produced world wide traditionally have been, and still remain, tomato and cucumber. Cucumber is by far the most important greenhouse crop in Russia.

Cucumbers,muskmelons, watermelons, and squash within, the past 2 decades, have come into prominence in many countries, particularly in China, Japan, Italy, Spain, Greece,Turkey,Tunisia, Morocco, and Egypt, with the expansion ofplastic greenhouses and tunnels (Wittwer, 1993). Further expansions in glass greenhouses during the past decade have been only in northern Europe. Tomato, with its many cultivars adapted to greenhouse culture, remains the most important of the solanaceous crops produced in the greenhouses of Holland, the Canary islands, and Morocco. The red bell sweet pepper is running a close second. This is particularly true in Holland, which is still the world's leader in glasshouse vegetablesandflower production, providing a current annual return of about $\$ 3$ billion. Peppers require lessspaceinheight and less training and pruning of the stems than tomatoes. They produce abundantly over an equally long season. Harvests can be spread further apart, thus requiring less labor. Finally, the bright red product has an expandingdomesticandforeign market. During the 1994 season in 
Holland, the value of the pepper crop anticipated to equal that of the tomato (Nederhoff, 1994).

Of all the fruit crops, the strawberry is preeminent for greenhouse and tunnel culture. It is widely grown in greenhouses and in high and low tunnels in Japan, China, and in almost all Mediterranean countries, including Israel. It can be seen under protective covers in most all small gardens of northern and central Europe. Grape production, evident 25 years ago in hundreds of small greenhouses north of Brussels in Belgium, largely has disappeared. Significant areas within greenhouses and rain shelters devoted to grapes and tree fruit (banana, citrus, pear, peach, plum, pineapple) are still found in Japan, Italy, Morocco, Spain (Canary Islands), and Portugal (Azores Islands). Salad crops, principally lettuce of various types, are grown in the greenhouses of northern Europe and Japan and in the eastern European countries of Russia, Poland, and Hungry. There is still a remnant of lettuce production in the greenhouses in the United States. Greenhouse culture of Chinese and ordinary cabbage may be seen in China, Japan, and Korea. Very minor quantities of celery, radish, and asparagus are found in the greenhouses of Germany, France, and Belgium. Some green beans are produced in the greenhouses of countries bordering the Mediterranean Sea and in China.

Production of flowers, bedding plants, potted plants, and ornamental constitute the largest and most recent takeover in greenhouse and tunnel culture. For the United States, $95 \%$ of greenhouse culture is now devoted to producing bedding plants, potted plants, cut flowers, foliage plants, and ornamental (Fig. 15). Of the total production of bedding plants, only $10 \%$ to $20 \%$ is vegetables, the balance being flowers. A similar, but less striking, transition is occurring in southern counties of the province of Ontario. The transition from vegetables to flower crops in the greenhouses of Holland, while formidable, is less dramatic than in the United States. In 1960, greenhouse vegetable production in Holland was about $90 \%$, but now it has declined to about $40 \%$, with the remaining percentages $45 \%$ for cut flowers and $15 \%$ for potted plants. Similar trends have occurred in Denmark and the United Kingdom, including the isle of Guernsey, and is now evident in the plastic greenhouses of the Mediterranean area and in China, Japan, and Korea.

Table 3 assesses the global status of protectedcultivation.Whilenodata are given, the most ancient widely used and those of greatest impact are windbreaks and irrigation. While millions of hectares of cropland, perhaps hundreds of million, have a degree of natural or artificial protection, the exact figures are not available. Their ancient and present use in China and the countries of the Middle East are recognized. Coupled closely with the rise of structures and materials for protective coverings of high-value crops has been the rise of drip or trickle irrigation. Although still only a small component of the approximate 250 million ha of the cultivated cropland of the earth, drip or trickle irrigation has become an integral part of most greenhouse and tunnel cultures as well as that of plastic mulches for high-value crops. The current level of trickle irrigation worldwide ranges from 1.5 to 2.0 million ha. This system of irrigation originated during 1950s in England, and was introduced in Denmark as a

\section{Droduction of flowers, bedding plants, potted plants, and ornamentals constitute the largest and most recent takeover in greenhouse and tunnel culture.}

Fig. 14. Protected cultivation in a home garden in Switzerland. 
patentedspaghetti system for greenhouse crop culture in 1959. It was further developed for open field applications by Israel during 1960s and began to have worldwide distribution by 1970 , with about 50,000 ha in 1974, expanded to about 400,000 ha by 1980 (Wittwer, 1981).

Second only to the use of windbreaks and irrigation is that of soil mulching, specifically the increased use of plastics as a soil mulch. Globally, the most significant development has been in China, where 1.4 million ha of cotton is mulched annually. Second in importance is peanuts, and more than $75 \%$ of the watermelons produced receive a plastic mulch plus wind protection wherever pos- sible. An explosive area for plastic mulching of many high-value crops is the Mediterranean region, particularly Spain, Italy, and France.

Floating rowcovers, requiring no wire support and consisting of spunbonded PP, have gained favor for plant protection, particularly in France and in northern Europe.

Low tunnels or wire-supported row covershave emerged during the past 2 decades as highly significant for the protection of row crops in China, Japan, and Korea. They can be seen for plant protection throughout the Mediterranean countries during winter and spring, as seas of plastic cover squash, muskmelons, and watermelons. Limited areas are

Table 1. Global assessment of protected cultivation using windbreaks and soil mulches and main horticultural crops involved (structure, crop, predominant country, and purpose).

Windbreaks (trees, canes, bamboo, crop residues, PE, PP, or other plastics)

Vegetables (tomato, strawberry, all vine crops, cucumber, melon, squash)

China, Japan, Korea,Taiwan, Israel, Portugal, Spain, Chile, Argentina, Russia, Ukraine, Morocco, France, Greece, Algeria, Belgium, Tunisia, Egypt, Jordan, United States, Canada

Mechanical protection, reduced evapotranspiration, increased yield

Fruit orchards (citrus, grapes, pear, kiwi)

China, Japan, Korea, Taiwan, Spain, Portugal, Italy, Argentina, Russia, Ukraine, Chile, France, Greece, Tunisia, Jordan, Algeria, Israel, United States, Canada

Mechanical protection, reduced evapotranspiration, increased yield

\section{Soil mulches}

Artificial (PE or other plastics)

Strawberry

China,Japan,UnitedStates,Taiwan,Spain,Italy,France,Portugal,Israel, Greece, Belgium, Argentina, Egypt, Turkey, Poland, C a n a d a

Weed control, earliness, water savings, increased yield andquality

Natural (straw, sand, gravel, living)

Tomato

United States, China, Japan, Taiwan, Italy, Spain, Korea, Morocco, Argentina,Egypt, Jordan,Israel, Canada

Weed control, earliness, water savings, increased yield and quality Melon

China, Japan, Taiwan, United States, Spain, Italy, Greece, France, Israel, Argentina, Egypt, Portugal, Hungary, Jordan, Canada Weed control, earliness, water savings, increased yield and quality

Artificial or natural

Watermelon

China, Spain, Greece, Japan, Korea, Taiwan, Portugal, Italy, Israel, Nigeria, United States, Canada

Weed control, earliness, water savings, increased yield and quaky

Cucumber

China, Japan, Korea, Taiwan, Egypt, Morocco, Poland, United States, Canada

Weed control, earliness, water savings, increased yield and quaky

Squash

China, Japan, Taiwan, Greece, Italy, Algeria, Jordan, United States, Canada

Weed control, earliness, water savings, increased yield and quality

Pepper

Italy, Morocco, Spain

Weed control, earliness, water savings, increased yield and quality

Asparagus

Spain, Greece, Belgium, Germany, Holland, China, Taiwan

Weed control, earliness, water savings, increased yield and quaky

Banana

Morocco, Spain (Canary Islands)

Weed control, earliness, water savings, increased yield and quaky

Sweetpotato

Nigeria

Weed control, earliness, water savings, increased yield and quality 
ne can view
the changing patterns of protected cultivation worldwide by several dimensions. will increase in importance in providing a stable, dependable, source of high-quality food products in a market that is becoming increasingly competitive.

One can view the changing patterns of protected cultivation worldwide by several dimensions. There has been, since ancient times, a continuing expansion in areas covered, going from a few small holdings 2 centuries ago in western Europe, the Far East, and North America, to commercial greenhouse food production. Several thousand acres are now under glass in the United States and equally large areas in England and Holland, where horticulture under glass was practiced over a century ago, with the production and marketing of tomatoes, grapes, cucumbers, and salad crops. By 1980, there were an estimated 150,000 ha of greenhouses (glass, plastic, fiberglass) in use globally for the production of high-value food crops (Wittwer 1981), and an almost equal area for flowers, potted plants, bedding plants, and other ornamental. Today, if one considers the vast expanses that have occurred in plasticulture during the past decade in China, Japan, Korea, and in all countries bordering the Mediterranean Sea and those in the southern hemisphere, the area comprising plants grown under protective covers (greenhouses and tunnels) exceeds 500,000 ha.

The changing pattern of protected cultivation is reflected in the crops produced. The most remarkable pattern is that of food crops consisting of vegetables and fruit, and on to flowers, potted plants, bedding plants, and other ornamental. All producing areas have seen an impact, with the most dramatic occurring in the past 2 decades in the United States, followed by Holland, the United Kingdom, and Denmark. That transition has been in progress since 1970 in Israel, the Isle of Guernsey, and in Japan. It is now occurring in France, Italy, Spain, and Greece, although the market demand can not allow a quick transition. Only recently have flowers and ornamental begun to replace greenhousegrown vegetable crops in China. No longer is lettuce an important greenhouse-grown crop in the United States. Its value has diminished in northern European countries, particularly Holland and the United Kingdom. There is only a remnant left of rhubarb forcing and the covering of celery plant rows with parchment paper in Michigan. A once-thriving industry of grape production in the glasshouses of Belgium is essentially nonexistent. Only Within the last decade has the sweet pepper emerged as a leading greenhouse-grown vegetable. Within the past 2 decades, major food and fiber crops have been subjected to the advantages of plasticulture. The world's most extensive use of plastic for protected cultivation is for soil mulching. In China, almost 2 million ha is devoted to cotton, peanuts, and covered rice seedbeds. Plastic soil mulches have also been used extensively for promoting earlier maturity and improved yields of maize in China and France. Plastic soil mulches have also proved useful for sweetpotato, pineapple, and cassava production in the tropics.

While production of crops in greenhouses and tunnels may be the most intensive in the valleys and hillsides of countries bordering the Mediterranean Sea and adjacent to the major cities in China, the United States and Russia, protective production is now spread over widely dispersed areas. Nowhere is this more evident than in the home gardens and commercial establishments of northern Europe. Greenhouse culture is now found in all the provinces, autonomous regions, and municipalities of China, in every state in the United States, almost all the provinces of Canada, and throughout Japan and Korea. It may be seen in such distance places as Kenya, Nigeria, Alaska, and all the major countries of the southern hemisphere (South Africa, Argentine, Chile, Colombia, Ecuador, Australia, and New Zealand).

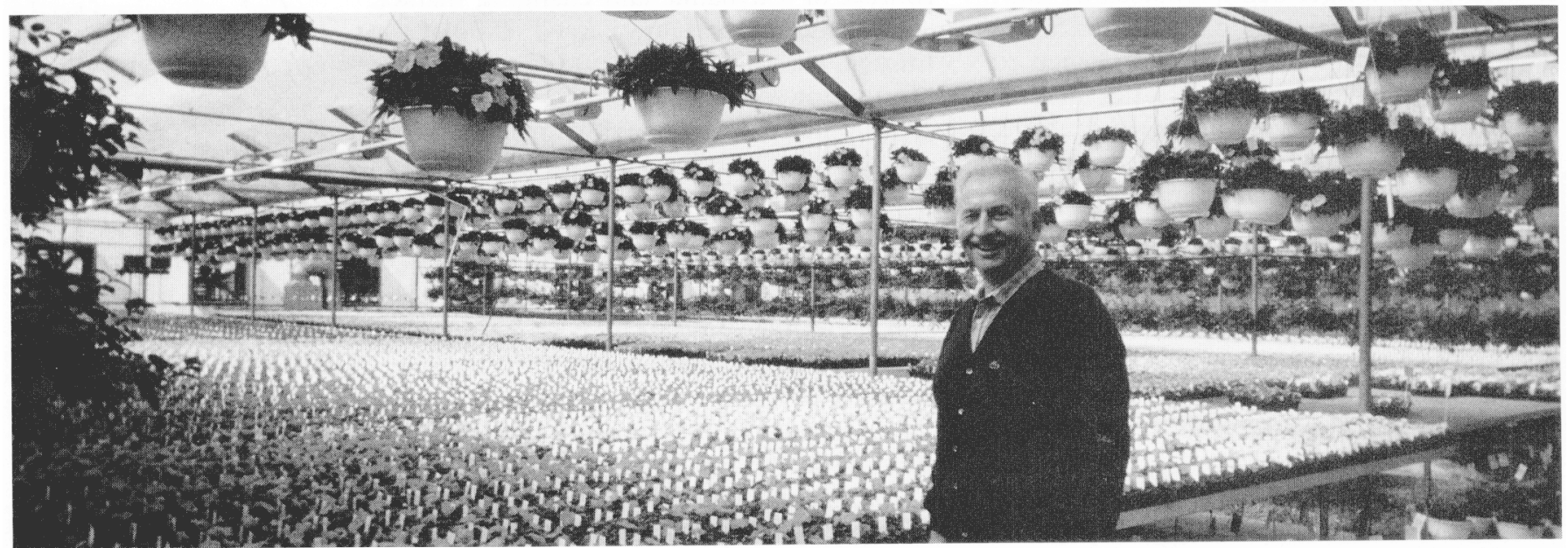

Fig. 15. Bedding plant production in the Frank Smith greenhouses, Carleton, Mich. 
Table 3. Global distribution of protected cultivation using biological and other structures or barriers.

\begin{tabular}{lrrrrr} 
& \multicolumn{4}{c}{ Geographical area } \\
\cline { 2 - 6 } Structure & \multicolumn{1}{c}{ Asia } & Mediterranean & North/South America Northern Europe & Total \\
\hline Plastic soil mulches & $3,080,000^{\prime}$ & 191,000 & $85,000^{\prime}$ & 15,000 & $3,371,000$ \\
Direct cover (floating types) & 5,500 & 10,300 & $1,500^{\prime}$ & 27,000 & 44,300 \\
Low tunnels (rowcovers) & 143,400 & 90,500 & 20,000 & 3,300 & 257,200 \\
High tunnels & & $27,600^{\circ}$ & & & 27,600 \\
Plastic greenhouses & 138,200 & 67,700 & 15,600 & 16,700 & 238,200 \\
Glasshouses & 3,000 & 7,900 & 4,000 & 25,800 & 40,700
\end{tabular}

Windbreaks Millions of hectares, globally. Exact figures not available. China and

Mediterranean countries predominate.

"Includes cotton, rice, and peanuts in China; corn in France; and rice seed beds in the Orient.

${ }^{y}$ Crude estimate only.

${ }^{x}$ High tunnels are often computed together with plastic greenhouses in countries other than Mediterranean. France is included in the Mediterranean group.

\section{A look to the future}

The inability of people to predict the weather and control the climate persists. This is accompanied by a rising population with increasing numbers of affluent and demanding people who insist on improved diets. Coupled with the above are limitations of land, water, energy, mineral nutrients, and the need for improved management of all resources. Thus, we will likely see a continuing increase in the extent and dispersion of protected cultivation throughout the world. Only within the past 2 decades have greenhouses, rowcovers, and plastic soil mulches attracted the attention of agriculturally developing countries in Asia, South America, and Africa. In the United States and Europe, protected cultivation commands the attention and interest of the professional and amateur gardener. For horticulturists, foresters, crop, and other scientists, it provides a site for testing and verification of new technologies for open field culture. The explosive use of plastic soil mulches in China for major field crops, including cotton, peanuts, and corn only within the past decade, is indicative of an expansion beyond the use only for high-value crops.

There will be new developments in the use of plastic and glass as covers for greenhouses. The Dutch are successfully developing new glass structures for improved transmission of sunlight. Innovations in the use of plastic for nonheated structures in the tropics and semi-tropics will appear. Biodegradable and light-degradable plastics will make their use more environmentally compatible.

The development of intelligent films will open new perspectives to protected cultivation (Garnaud, 1994). There will be films that limit the transmission of infrared solar radiation $(700-900 \mathrm{~mm})$, thereby reducing the greenhouse effect in tropical areas, where limiting the air temperature may be desirable, or films that reconvert the radiation from the photosynthetically inactive wave lengths of the solar energy spectrum into PAR to improve crop productivity.

New labor-saving technologies, even beyond those now in the plant-growing and bedding plant industries in the United States, will become commonplace and even more specialized. The thermomorphogenic and photoperiodic responses of crops grown in greenhouses and other protective structures, and the interaction of these responses to other environmental variables (sunlight, humidity, mineral nutrient status, elevated levels of atmospheric $\mathrm{CO}_{2}$ ), are as yet little known (Bakker, 1991; Erwin et al., 1993).

Unique developments will appear in the handling of conventional and innovative commodities. New high-value crops may replace the conventional, as is now occurring, with red sweet peppers now replacing tomatoes. Alternatively, tomatoes may find new life in the extended shelf life of Calgene's "Flavor Saver" and the Pioneer Vegetable Genetics Super Life (Derrer et al., 1994; Oeller et al., 1991).

There will be a continuing expansion in flower and ornamental crop production to meet the needs and desires of people for home and community beautification. The examples set by the Dutch in maximizing production of vegetable crops and those in the United States in the regulation of day and night temperatures and in mechanization of seeding and transplanting of seedlings, coupled with the other components of the greenhouse environment for bedding plants and flower crops, will keep protected cultivation a viable option to open field agriculture.

\section{Literature Cited}

Bakker J.C. 1991. Analysis of humidity effects on growth and production of glasshouse fruit vegetables. Glasshouse Crops Res. Sta., Naaldwijk, The Netherlands.

Benoit, F. and N. Ceustermans. 1985. Unsupport-ed covering with perforated plastic films growing spring vegetables: A review. Plasticulture 67:4348.

\section{Te will likely see a con- tinuing increase in the extent and dispersion of protected culti- vation through- out the world.}


Boyer, J.S. 1982. Plant productivity and the environment. Science 218:443-448.

Castilla, N. (cd. ). 1992. Country papers. In: Proc. XII Intl. Congr. Plastics in Agr. Cepla, Madrid. A:1-110.

Castilla, N. 1994. Greenhouses in the Mediterranean area:Technologicallevelandstrategic management. Acts Hort. (In press. )

Castilla, $N$ and E. Fereres. 1990a. Tomato growth and yield in unheated plastic greenhouse under Mediterranean climate.Agr. Mediterranea 120:3140.

Castilla, N. and E. Fereres. 1990b. The climate and waterrequirementsof tomato in unheated plastic greenhouses.Agr.Mediterranean120:268-274.

Castilla, N., C. Jimenez, and E. Fereres. 1986. Tomatoroot development on sand mulch, plastic greenhousein Almeria. Acts Hort. 191:11 3-1 21.

Castilla, N., F. Tognoni, and C.M. Olympios. 1992. Vegetable production under simple structures in southern Europe. Food Fert. Technol. Centre, Taipei, Bul. 348 .

Comite des Plastiques en Agriculture. 1992. Les plastiquesenagriculture.CPA, Paris.

Dahyw.pie, D. G. 1973. Controlled environment agriculture: A global review of greenhouse food production.Econ.Res. Serv., USDA Foreign Agr. Econ. Rpt. 89.

Decoteau, D.R. 1989. Mulch surface color affects yield of fresh-market tomatoes. J. Amer. Soc. Hort. Sci. 114:216-219.

Derrer, D. 1994. Flavor Saver, Super Life take the stage.American Vegetable Grower 42(8 ) :24-25, 48.

E1-Aidy, F. 1992. Protected cultivation in Saudi Arabia. Plasticulture 94:(2):7-11.

Enoch, H.Z. 1986. Climate and protected cultivation. Acts Hort. 176:11-20.

Erwin, J. E., R.D. Heins, and M.G. Karlsson. 1989. Thermomorphogenesis in Lilium longiflorum Thun. 'Nellie White'. Amer. J. Bot. 76(1):47-52.

Erwin, I. E., R.D. Heins, and J.E. Faust. 1993. Thermomorphogenic and photoperiodic responses of Nephrolipis exaltata. Dallas Jewel. HortScience 28:182-184.

FAO. 1986. Brise-vent et rideaux abris avec reference particuliere aux zones seches. Cahier FAO conservation no. 15. FAO, Rome.

Garnaud, J. C. 1987. A survey of the development of plasticulture: Questions to be answered. Plasticulture74:5-14.

Garnaud,J.C. 1994. L'etat de l'art de la plasticulture. In: Proc. XIII Intl. Congr. Plastics in Agr. Verona, Italy. (In press. )

Geinsenberg, C. and K. Stewart. 1986. Field crop management, p. $511-557$. In: The tomato crop. J.G. Atherthon and J. Rudich (eds.). Chapman and Hall, London.
Germing, G.H. 1985.Greenhouse design and cladding materials: A summarizing review. Acta Hort. 170:253-257.

Giaccomelli, G.A. and W.J. Roberts. 1993. Greenhouse covering systems. HortTechnology 3:5058.

Heins, R.D. and J.E. Erwin. 1990. Understanding andapplyingDIF.GreenhouseGrower,Feb.1990, p. $73-78$.

Jensen, M.H. and W.L. Collins. 1985. Hydroponic vegetable production. Hort. Rev. 7:483-558.

Katan, J. 1980. Lutte contre les maladies du sol a llaide d'un paillis de polyethylene. Plasticulture 46:2-6.

Lamont. W.J. 1993. Plastic mulches for the productionofvegetablecrops. HortTechnology 3:3539 .

Lamont, W.J., K.A. Sorensen, and C. W. Averre. 1990. Painting aluminum strips on black plastic mulch reduces mosaic symptoms on summer squash. HortScience 25:1305.

Melero, J. M., R. Gonzalez, J. Gontez, J. Bejarano, and M.J.Basallote.1989. Lasolarisationdessols en Andalusie grace au film plastique. Plasticulture 82:73-82

Nederhoff E.M. 1994. Effects of $\mathrm{CO}_{2}$ concentrationonphotosynthesis, transpirationandproduction of greenhouse fruit vegetable crops. Glasshouse Crops Res. Sta., Naaldwijk, The Netherlands.

Nelson,P.V.1985. Greenhouseoperationandmanagement. Prentice-Hall, NewBrunswick, NJ.

Nisen, A., M. Grafladellis, R. Jimenez, G. La Malfa, P.F. Martinez-Garcia, A. Monteiro, H. Verlodt, O. Villele, C.H. Zabeltitz, I. U. Denis, and W.O. Baudoin. 1990. Protected cultivation in the Mediterranean climate. Plant Prod. Protection Paper 90. FAO, Rome.

Nishi, S. 1986. Protected horticulture in Japan. Jpn. Greenhouse Hort. Assn., Tokyo.

Oeller, P. W., Lu Min-Wong, L.P. Taylor, D.A. Pike, and A Theologis. 1991. Reversible Inhibition of tomato fruit senescence by antisense RNA. Science 254:437-439.

Olympios, C.M. 1991. The situation of protected cultivation in Greece. Plasticulture 91(3) :5-16.

Postel, S. 1989. Water for agriculture: Facing the limits. Worldwatch paper 93. Worldwatch Inst., Washington, D.C.

Postel, S. 1993. Facing water scarcity. State of the world. Norton, New York. p. 22-41.

Romanowski, R.R. 1981. Environmental control structures. Vegetable farming systems in China. Westview, Boulder, Colo. p. 119-127.

Rosenberg, N.J. 1974. Microclimate: The biologicalenvironment.Wiley,New York.

Rosenberg, N.J. 1979. Windbreaks for reducing moisture stress, p. 394408. In: B.J. Barfield and 
J.F. Gerber (eds.). Modification of the aerial environmentof plants. Amer. Soc. Agr. Eng. Monogr. 2 .

Schales,F.D.1990. Agricultural plastics use in the United States. Proc. XI Intl. Congr. Plastics in Agr. New Delhi, India. p. J.54-J.56

Seginer, I.1993. Crop models in greenhouse climate control. Acts Hort. 328:79-98.

Tognoni,F. (cd.). 1991. La situazione delle colture protette nei paesi mediterranei. Colture Protette $10: 37-88$.

Tognoni, F. G. and G. Serra. 1989. The greenhouse in horticulture: The contribution of biological research. Acts Hort. 245:46-52.

Van Eimtern, J., R. Karachon, L.A. Razumova, and G.W. Roberston. 1964. Windbreaks and shelterbelts.WorldMeteorol.Org.,Geneva,Tech. Note no. 59.

Wells, O.S. and J.B. Loy. 1985. Intensive production with row covers. HortScience 20:822-826.
Wittwer, S.H. 1981. Advances in protected environmentsfor plant growth. In: Advances in foodproducing systems for arid and semi-arid lands. Academic, New York.

Wittwer,S.H.1986. Worldwidestatusandhistory ofCO ${ }_{2}$ enrichment-an overview, p. 3-1 5. In: HZ. Enock and B.A. Kimball (eds.). Carbon dioxide enrichmentofgreenhousecrops.vol. 1. Status and $\mathrm{CO}_{2}$ sources. CRC Press, Boca Raton, Fla.

Wittwer, S.H. 1993. World-wide use of plastics in horticultural production. HortTechnology 3:6-19.

Wittwer, S.H. and S. Honma 1979. Greenhouse tomatoes, lettuce and cucumber. Michigan State Univ.Press, East Lansing.

Wittwer, S.H. and W. Robb.1964. Carbon dioxide enrichment of greenhouse atmospheres for food crop production. Econ. Bet. 18:34-56.

Wittwer, S. H., T. Youtai, W. Lianzheng, and S. Han. 1987. Feedingabillion:Frontiers in Chinese agriculture.MichiganStateUniv.Press,East Lansing. 